\title{
STUDY OF THE EFFECT OF THE HEAT TREATMENT PARAMETERS ON THE PEARLITIC TRANSFORMATION OF AN EUTECTOID STEEL WIRE
}

\author{
${ }^{1}$ Laís ÁVILA DE OLIVEIRA SILVA, ${ }^{2}$ Christophe MESPLONT, ${ }^{1}$ Jérémie BOUQUEREL, \\ 1 Jean-Bernard VOGT \\ ${ }^{1}$ Univ. Lille, CNRS, INRAE, Centrale Lille, UMR 8207 - UMET - Unité Matériaux et Transformations, France, \\ EU, jean-bernard.vogt@centralelille.fr \\ ${ }^{2}$ Bekaert NV, Zwevegem, Belgium, EU
}

https://doi.org/10.37904/metal.2021.4129

\begin{abstract}
High carbon steel wires are largely used in structural applications such as reinforcement, bridge cables, steel ropes, etc. These applications require safety, reliability and durability, which implies in a constant effort to optimize and control the microstructure. The correct managing of the different steps of heat treatments is essential to achieve these aims. To address this problem, this study brings a critical investigation of the heating, from room temperature to austenitizing temperature, and cooling, from the austenitic domain to room temperature, of an eutectoid steel wire. Dilatometry with strict control of heating and cooling rates was employed to measure the variations in length in order to detect the minor changes in the microstructure and to explore the phase transformation features. The microstructure investigation by optical and scanning electron microscopy complemented with hardness allowed to evaluate the prior austenite grain size (PAGS) and homogeneity variations with heating rates, soaking time and temperature of austenitization. Their effect on the pearlitic transformation and the pearlite morphology, both at isothermal and continuous cooling, were also surveyed. While the heating rates do not seem to play an important role on the PAGS in the considered range, the results of the duration suggest a real effect on grain size, which are discussed based on diffusion process and by considering the time-temperature equivalences. The results collected in this work present guidelines for industrial practice and endorse the importance of parameters' control in a heat treatment.
\end{abstract}

Keywords: High carbon steels, phase transformations, pearlite, austenitization, dilatometry

\section{INTRODUCTION}

The use of pearlitic steel wires in structural applications demand a constant improvement of the production system and the microstructure of the steels. There are several studies on low carbon steels aiming the control of the production parameters, which have not been widely explored to high carbon steel [1-6].

The control of the pearlitic microstructure is mostly focused on the interlamellar spacing and its effect on the mechanical properties, which had already been largely proved to decrease with the degree of undercooling and thus improve the yield strength [7]. There are many other pearlite features, such as colony and nodule size, alignement of the lamellaes or the presence of branching and bridging between the cementite lamella, which had already been reported to exist but that still needs to be further characterized and explained [8-10]. Besides, there is still a gap of knowledge within the effect of austenitizing parameters on the pearlite transformation and the further effect of it on the retransformation to pearlite.

This work intends to address this gaps by means of a dilatometry study of the phase transformations of pearlite during heating and cooling considering the industrial practices with the aim to propose some improvements. 


\section{MATERIALS AND EXPERIMENTAL PROCEDURE}

The studied wire is a perlitic plain carbon steel with (in wt\%) $0.82 \mathrm{C}, 0.56 \mathrm{Mn}, 0.28 \mathrm{Si}$ and Fe balanced, cold drawn from 6.5 to $4 \mathrm{~mm}(\varepsilon=0.97)$. The initial state of the studied steel is an important definition since it is known to affect the final microstructure, even after the full austenitization cycle [11]. It is especially important in this work since the samples were directly cut from the wires to produce the $10 \mathrm{~mm}$ long cylinders for the dilatometry tests. It does not follow the ASTM standard A1033-18 that states a sample production method to avoid the effect of texture [12], which implies that the reported observations are only valid considering its amount of deformation.

The phase transformations critical temperatures were characterized in a quenching dilatometer DIL 805 . The accuracy of the data extraction is extremely dependent of the method, as already discussed in the literature [13-15]. The chosen method to extract the critical temperatures of the dilatometry curves in most cases was the lever rule due to its simplicity and efficacy when applied to well-defined single transformation. The calculated transformed fraction was not considered because of multi-transformations events observed in the continuous cooling experiments, which would lead to wrong conclusions. The offset method [15] was used only for Ms because, as the transformation does not reach the end, the use of the lever rule was compromised and presented a larger scattering.

The intention of this study was to understand the effect of the heating parameters on a deformed pearlitic microstructure and then define how they affect the pearlite produced afterwards. To cover a significant number of parameters, the cycles were defined aiming to produce the heating diagrams, Time-TemperatureAustenitizing (TTA) and Continuous-Heating-Transformation (CHT), in which the soaking times (10,60 and $300 \mathrm{~s})$, temperature $\left(900,950\right.$ and $\left.1000^{\circ} \mathrm{C}\right)$ and heating rates $\left(1,5,10,50\right.$ and $\left.100^{\circ} \mathrm{C} / \mathrm{s}\right)$ were analyzed.

Two austenitization cycles $\left(30{ }^{\circ} \mathrm{C} / \mathrm{s}\right.$ to $950{ }^{\circ} \mathrm{C}$ and $5{ }^{\circ} \mathrm{C} / \mathrm{s}$ to $1000{ }^{\circ} \mathrm{C}$ ) were used to produce the cooling diagrams: The Time-Temperature-Transformation (TTT), using ten isothermal temperatures between $640^{\circ} \mathrm{C}$ to $460{ }^{\circ} \mathrm{C}$ with 2 minutes of holding time, and the Continuous-Cooling-Transformation (CCT), for which were performed six cooling rates $\left(5,10,20,30,50\right.$ and $\left.100^{\circ} \mathrm{C}\right)$.

The pearlite was characterized by the average interlamellar spacing $(\overline{S)}$ and microhardness. While for the martensite the prior austenite grain size (PAGS), the microhardness and Ms were used.

\section{RESULTS}

\subsection{Heating}

The results from the dilatometry curves are shown in Figure 1. The start of transformation temperature $\left(\mathrm{Ac}_{1}\right)$ is not strongly affected by the heating rates, always being around $730{ }^{\circ} \mathrm{C}$ for the considered range, which implies that the nucleation is not strongly affected. While the end of transformation $\left(A_{3}\right)$ was clearly affected, ranging from 750 to $790^{\circ} \mathrm{C}$ and, at $100^{\circ} \mathrm{C} / \mathrm{s}$, it was not even possible to define the critical temperatures. The time to transform also changed, from almost $20 \mathrm{~s}$ at $1{ }^{\circ} \mathrm{C} / \mathrm{s}$ and less than $1 \mathrm{~s}$ at $50{ }^{\circ} \mathrm{C} / \mathrm{s}$. It evidences that the growth of the austenite into the pearlite, which has already been reported to be fast [19], is the most affected stage. This effect is probably seen by the temperature of carbide dissolution (Acc) too, however, due to the large scattering of methods to measure this critical temperature, it was not measured in this work. This effect in the $\mathrm{Ac}_{3}$ has already been reported for low carbon and high manganese steels [2].

Another important feature observed in this curve is the shape of the curve before the austenitic transformation. The variations of the dilatometry curve before the transformation in low carbon steels was reported to be the either the detection of texture evolution, recrystallization and/or recovery [1]. In Figure 1, a change in the slope can be observed but there is no exact definition of which phenomena would be happening in the case of high carbon steels. 


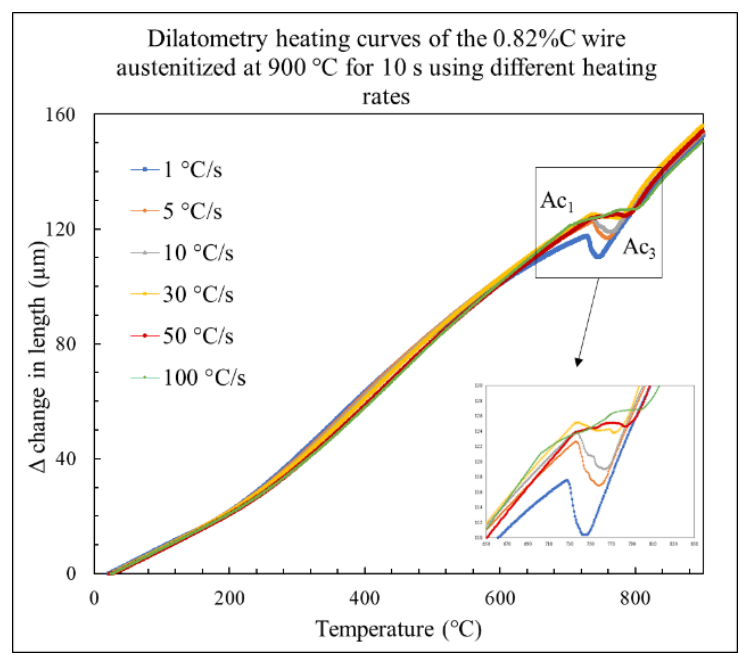

Figure 1 Dilatometry curves of the heating at different heating rates to $900{ }^{\circ} \mathrm{C}$

The PAGS obtained at different times and temperatures presented a significant variation of the grain size with both parameters, which was already expected considering that only diffusive phenomena were involved and they are time and temperature depend. In contrast with these results, the different heating rates did not show a considerable variation nor tendency. Considering that only the austenitic transformation would happen and that it is a diffusive transformation, Manier [20] proposed that is possible to calculate two equivalent cycles of equivalent temperatures and times that would produce the same PAGS. It is a quite simplified theory since other phenomena can happen during heating and it would entail in other use of energy and not exclusively use to transform. The equation of the equivalent cycles $\left(T_{0}, t_{0}\right)$ and $(T, t)$, in which $T>T_{0}$, is:

$$
t \cdot \exp \left(\frac{\Delta H}{R T}\right)=t_{0} \cdot \exp \left(\frac{\Delta H}{R T_{0}}\right)
$$

where:

$$
\begin{aligned}
& \mathrm{t} \text { - the time in the austenitization temperature } \mathrm{T}(\mathrm{s}) \\
& \mathrm{T} \text { - the temperature of austenitization (K) } \\
& \mathrm{R} \text { - the gas constant (Constant and equal to } 8.314 \mathrm{~J} / \mathrm{K} \cdot \mathrm{mol} \text { ) } \\
& \Delta \mathrm{H} \text { - is the activation energy (considered constant and equal to } 460550 \mathrm{~J}) \text { [20] }
\end{aligned}
$$

The equivalent cycle to $900{ }^{\circ} \mathrm{C}$ for $300 \mathrm{~s}$ would be either a cycle at $950{ }^{\circ} \mathrm{C}$ for $45 \mathrm{~s}$ or at $1000{ }^{\circ} \mathrm{C}$ for $9 \mathrm{~s}$. The tested times are not exactly the same, but the values of PAGS are very close when treated at $900{ }^{\circ} \mathrm{C}$ for 300 $\mathrm{s}, 950^{\circ} \mathrm{C}$ for $60 \mathrm{~s}$ and $1000^{\circ} \mathrm{C}$ for $10 \mathrm{~s}$, which is $62 \mu \mathrm{m}, 56 \mu \mathrm{m}$ and $52 \mu \mathrm{m}$, respectively, with $\pm 8 \mu \mathrm{m}$ of standard deviation. Although the ANOVA test detected a significant difference of $7 \mu \mathrm{m}$ with $95 \%$ of confidence, it still suggests that the data shows an agreement with the calculation. It would be important to do it for a wider range of the exact equivalent cycles, as done in the article, and consider the standard deviation of the PAGS. Despite its simplicity, this method of predicting PAGS can be a useful tool for industrial applications and control. The homogeneity of the austenite can be indirectly measured both by the hardness and Ms temperature. With the increase of the amount of carbon in solid solution, the hardness increases while the Ms decreases. The hardness results did not present any significant difference between the heating rates, but the values at $900{ }^{\circ} \mathrm{C}$ for $10 \mathrm{~s}$ is lower than 950 and $1000{ }^{\circ} \mathrm{C}$. It indicates that the austenitization would reach its maximum carbon dissolution from $900{ }^{\circ} \mathrm{C}$ for $60 \mathrm{~s}$ or $950^{\circ} \mathrm{C}$ for $10 \mathrm{~s}$. The measured Ms did not show a difference using the offset method, which is expected since all the cooling curves are coincident. Therefore, by this method, there are no variations of austenite homogeneity between the different austenitization cycles. Comparing this result with the hardness, there is a difference that was either not detected by the dilatometer or the method of data 
extraction was not sufficiently accurate. When measured by other methods, it could present a difference of even $40{ }^{\circ} \mathrm{C}$ but not with the same tendencies presented by the the hardness, which, again, proves the importance of reliable methods to interpret the dilatometer data.

\subsection{Cooling}

The study of the cooling was done by means of production of the CCT and TTT diagrams and the results are shown in Figure 2 below.
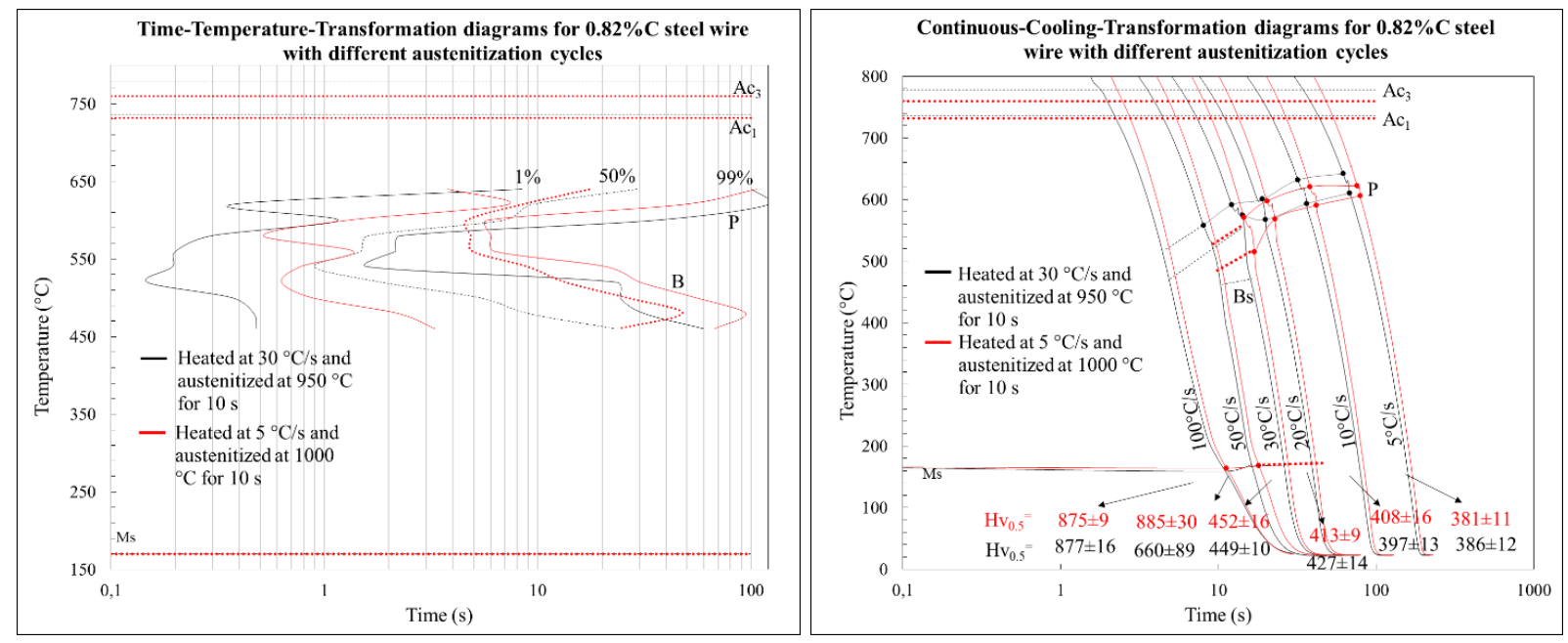

Figure 2 Overlaid Time-Temperature-Transformation (TTT) and Continuous-Cooling-Transformation (CCT) diagrams treated at different austenitizing cycles.

First the in TTT, the times to start the transformation is shifted for the samples austenitized at $1000^{\circ} \mathrm{C}$, which can be explained by the larger grain size that results in a decrease of the nucleation sites. The values of average interlamellar spacing $(\bar{S})$ and hardness did not a present a remarkable difference between the two cycles, $\bar{S}=175 \pm 41 \mathrm{~nm}$ for the coarser pearlite produced and $\bar{S}=104 \pm 8 \mathrm{~nm}$ for thinner ones.

The pearlite formed during continuous cooling presented a smaller $\bar{S}$ for the samples austenitized at $1000{ }^{\circ} \mathrm{C}$ compared to $950{ }^{\circ} \mathrm{C}$, being $101 \pm 14 \mathrm{~nm}$ and $90 \pm 13 \mathrm{~nm}$ for the coarser pearlite formed during cooling at $5{ }^{\circ} \mathrm{C} / \mathrm{s}$; and $84 \pm 8 \mathrm{~nm}$ and $78 \pm 4 \mathrm{~nm}$ for the fine pearlite cooled at $30^{\circ} \mathrm{C} / \mathrm{s}$ and austenitized at $950{ }^{\circ} \mathrm{C}$ and $1000{ }^{\circ} \mathrm{C}$ respectively. The CCT results had shown differences in the phase fields of the martensite, although it was previously concluded by the TTA and CHT that there is no difference in the homogenization between the cycles at 950 and $1000^{\circ} \mathrm{C}$ for $10 \mathrm{~s}$. The critical cooling rate for the samples autenitized at $950{ }^{\circ} \mathrm{C}$ is $30^{\circ} \mathrm{C} / \mathrm{s}$ while for the ones austenitized at $1000{ }^{\circ} \mathrm{C}$ is $20^{\circ} \mathrm{C} / \mathrm{s}$. It is most likely cause by the difference of PAGS that influences on the pearlite nucleation. These differences are evidenced in the micrographs shown in Figure 3.

Additionaly, bainite was formed when the wire was austenitized at $950^{\circ} \mathrm{C}$, which has been reported to indicate inhomogeneity in the prior austenite in hypoeutectoid steels [21]. It happens because proeutectoid ferrite regions are the last ones to transform to austenite and these regions with less carbon tend to transform to bainite during the cooling. In the current work, an hypereutectoid was analyzed and it seems to also be related to inhomogeneity since it is seen only for lower austenitizing temperature. Therefore, it is attributed to a higher hardenability due either to a more homogeneous distribution of carbon in solid solution. The pearlite produced by the isothermal treatment was degenerated, even with the decrease of the transformation temperature. While the ones produced by continuous cooling had kept its lamellar morphology with a considerable amount of branching and bridging between the cementite lamella. It was enhanced with the decrease of the cooling rates for both austenitization cycles, although more numerous for the samples austenitized at $950{ }^{\circ} \mathrm{C}$. Moreover, they were thinner due to a stronger undercooling, which could represent an advantage for the industrial 
practice. It would be interesting to evaluate the mechanical properties of the pearlite formed by both ways to confirm if it represents any advantage, especially in the work hardening, since the high mechanical of pearlitic wires is mostly because of the deformation of the patented wires. These results prove that the austenitization cycle has an effect on the final pearlitic transformation when starting from a pearlitic drawn wire. No much research have been done to elaborate the effects of the pearlite morphology in the transformation to austenite besides the differences between lamellar and spherodized pearlite.
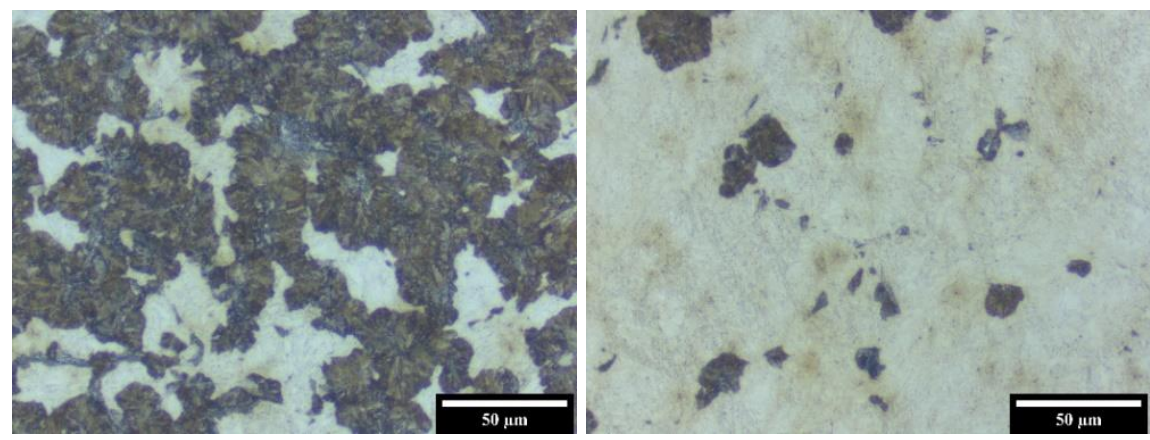

Figure 3 Micrographs of the CCT samples for $0.82 \mathrm{wt} \%$ of $\mathrm{C}$ cooled at $50^{\circ} \mathrm{C} / \mathrm{s}$ and austenitized at (a) $950^{\circ} \mathrm{C}$ and (b) at $1000^{\circ} \mathrm{C}$.

\section{CONCLUSION}

The study of the heat treatments parameters on the final microstructure are extremely important and this work have shown the effects both at heating and cooling of the pearlitic steels.

- $\quad$ There is a clear of effect of time and temperature on the PAGS in the considered range. From the Ms measurements, there is no variations in the homogeneity of austenite but, from the hardness values, from $900{ }^{\circ} \mathrm{C}$ for $60 \mathrm{~s}$ or $950^{\circ} \mathrm{C}$ for $10 \mathrm{~s}$, it is homogeneous. The heating rates do not seem to influence neither at the PAGS or the homogenization of the transformed austenite.

- $\quad$ The data had shown some agreement with a simplistic method for predicting the PAGS that works as easy and fast way to evaluate an austenitization cycle for the industrial practice reality.

- $\quad$ Both continuous and isothermal cooling were affected by the austenitization cycle. In the continuous cooling, the presence of bainite and changes in the fields of transformation represented variations in the homogeneity of the parent austenite. For the isothermal treatments, the kinetics was shifted to longer times because of the variation in grain that results in less nucleation sites for pearlite. The pearlite presented different morphologies, in the isothermal cooling it varied from long parallel lamella to degenerated pearlite. While in the continuous cooling, it presented long parallel morphology for all the cooling rates with a presence of bridging and branching.

- In this work are evidenced the gaps of knowledge of the eutectoid steel transformation, such as the effect of the different pearlite morphology obtained by different methods, explanations of the phenomena before the austenitization for the pearlitic structures and how are bridging and branching formed.

\section{ACKNOWLEDGEMENTS}

\section{The authors thank Bekaert for the permission and for the incentive to publish this article.}

\section{REFERENCES}

[1] De COCK, T., CAPDEVILA, C., CABALLERO, F. G., and De ANDRÉS, C. G. Interpretation of a dilatometric anomaly previous to the ferrite-to-austenite transformation in a low carbon steel. Scr. Mater. 2006, vol. 54, no. 5, pp. 949-954. 
[2] OLIVEIRA, F. L. G., ANDRADE, M. S., and COTA, A. B. Kinetics of austenite formation during continuous heating in a low carbon steel. Mater. Charact. 2007, vol. 58, no. 3, pp. 256-261.

[3] LEE, S. J. and LEE, Y. K. Prediction of austenite grain growth during austenitization of low alloy stels. Mater. Des. 2008, vol. 29, no. 9, pp. 1840-1844.

[4] ZHAO, C., YANG, K., XIAO, F. R., and SHAN, Y. Y. Continuous cooling transformation of undeformed and deformed low carbon pipeline steels. Mater. Sci. Eng. A. 2003, vol. 355, no. 1-2, pp. 126-136.

[5] MOHANTY, R. R., GIRINA, O. A., and FONSTEIN, N. M. Effect of heating rate on the austenite formation in low-carbon high-strength steels annealed in the intercritical region. Metall. Mater. Trans. A Phys. Metall. Mater. Sci. 2011, vol. 42, no. 12, pp. 3680-3690.

[6] MARDER, A. R. and BRAMFITT, B. L. The effect of morphology on the strength of pearlite. Metall. Trans. A. 1976, vol. 7, no. 2, pp. 365-372.

[7] ZHANG, M. X. and KELLY, P. M. The morphology and formation mechanism of pearlite in steels. Mater. Charact. 2009, vol. 60, no. 6, pp. 545-554..

[8] TAKAHASHI, T., PONGE, D., and RAABE, D. Investigation of orientation gradients in pearlite in hypoeutectoid steel by use of orientation imaging microscopy. Steel Res. Int. 2007, vol. 78, no. 1, pp. 38-44.

[9] SUNDQUIST, B. E. The edgewise growth of pearlite. Acta Metall. 1968, vol. 16, no. 12, pp. 1413-1427..

[10] DURGAPRASAD, A. et al. Defining a relationship between pearlite morphology and ferrite crystallographic orientation. Acta Mater. 2017, vol. 129, pp. 278-289.

[11] KAMYABI-GOL, A., HERATH, D. and MENDEZ, P. F. A comparison of common and new methods to determine martensite start temperature using a dilatometer. Can. Metall. Q. 2017, vol. 56, no. 1, pp. 85-93.

[12] ASTM A1033-18, Standard Practice for Quantitative Measurement and Reporting of Hypoeutectoid Carbon and Low-Alloy Steel Phase Transformations. ASTM International. West Conshohocken, PA, 2018.

[13] KHODAIE, N., IVEY, D. G. and HENEIN, H. "Unit cell dilation technique for analyzing dilatometry data in microalloyed steels. Mater. Charact. 2018, vol. 135, no. November 2017, pp. 84-95.

[14] KAMYABI-GOL, A., CLARK, S. J., GIBBS, J. W., SRIDHAR, S., and MENDEZ, P. F. Quantification of evolution of multiple simultaneous phase transformations using dilation curve analysis (DCA). Acta Mater. 2016, vol. 102, pp. 231-240.

[15] YANG, H.-S. and BHADESHIA, H. K. D. H. Uncertainties in dilatometric determination of martensite start temperature. Mater. Sci. Technol. 2007, vol. 23, no. 5, pp. 556-560.

[16] Astm Standard, "E112-12:Standard Test Methods for Determining Average Grain Size," ASTM Int. 2012 , vol. E112-12, pp. 1-27.

[17] American Society for Testing and Materials, "ASTM E407-07e1: Standard practice for microetching metals and alloys, in Annual Book of ASTM Standards. 2007.

[18] VANDER VOORT, G. F. and ROÓSZ, A. Measurement of the interlamellar spacing of pearlite. Metallography. 1984, vol. 17, no. 1, pp. 1-17.

[19] LI, Z., WEN, Z., SU, F., ZHANG, R., and ZHOU, Z. Dilatometric research on pearlite-to-austenite transformation of Fe-1C-1.44Cr low-alloy steel. J. Mater. Sci. 2018, vol. 53, no. 2, pp. 1424-1436.

[20] MAYNIER, P., TOITOT, M., DOLLET, J., and BASTIEN, P. Application des lois de la diffusion aux traitements thermiques de l'acier. Mem Sci Rev Met. 1972, vol. 69, no. 7-8, pp. 501-511.

[21] KESTER, Clarke The Effect of Heating Rate and Microstructural Scale on Austenite Formation, Austenite Homogenization, and As-quenched Microstructure in Three Induction Hardenable Steels. Colorado School of Mines, 2008. 